\title{
Geophysical Investigation of a Fault Zone from Aeromagnetic Data over the Ageva Area of Okene Kogi State, Nigeria
}

\author{
Ahmed A Lawal ${ }^{1}$, Adamu Abubakar ${ }^{1}$ and Avazi O Victor ${ }^{1}$ \\ ${ }^{1}$ Department of Physics, Ahmadu Bello University, Zaria, Kaduna State, Nigeria \\ ${ }^{2}$ Department of Applied Geophysics, Federal University Birnin Kebbi, Kebbi State, Nigeria \\ Corresponding E-mail: aminuahmad777@gmail.com
}

Received 22-04-2021

Accepted for publication 05-07-2021

Published 07-07-2021

\begin{abstract}
High-resolution aeromagnetic data over a part of Ageva fault zone in Nigeria have been analyzed with a view to estimate sedimentary thicknesses within the studied area. The data set of this study area, was subjected to various corrections and interpretation techniques. Regionalresidual correction was done and the noise level of the data was reduced via upward continuation to a height of $250 \mathrm{~m}$ thereby enhancing the reliability of the results obtained. Qualitative interpretation techniques which include: Second Vertical Derivative, Analytic Signal, Tilt derivative were used to delineate the trending pattern of the anomalies in the study area which are in the E-W, NE-SW, NW-SE, and N-S directions. The result suggests that fault zone within Ageva and Owo may be mineralized and also that the faults within Ageva and Ibilo extend by a quarter of their exposed length. The Werner solutions revealed that inferred faults within Owo and Ibilo may have relatively low susceptibilities as compared with others in the study area and the range of the depth extent of linear features is $401.5 \mathrm{~m}-982.5 \mathrm{~m}$.
\end{abstract}

Keywords: Regional-Residual Separation; Second Vertical Derivative; Analytic Signal; Werner Deconvolution; Euler Deconvolution and Contact - dyke

\section{INTRODUCTION}

$\mathrm{T}$ he structural interpretation of geophysical data aims at mapping joints and faults by lineament interpretation of processed potential field data or enhanced remotely sensed images. Aeromagnetic data reflects the distribution of magnetic minerals in bedrock and is unaffected by nonmagnetic cover. Aeromagnetic data can be used along with conventional geological maps for various earth resource evaluation applications [1]. The interpretation of aeromagnetic survey has served as basis for revealing the structural pattern of the basement complex, revealing the shallower structures, tracing lithological contacts and recognizing structures like faults, lineaments, dykes and layered complexes [2]. Some indicators that have been found useful in the exploration of minerals include: faults, fractures, and linear, arched or domed strata, oxidized \& hydrothermally altered areas [3].

Surface expression of a fault was observed at the Ageva village of Okene; near the Akumari hill and based on available literature, the fault observed in the area of interest has not been previously investigated in terms of i.e.: depth and size. In this regard, applying various qualitative and quantitative data transformations as upward continuation, vertical and horizontal derivatives, analytic signal and Werner in lineament interpretation from the aeromagnetic data over study area and its environs would delineate and characterize the faults; giving a regional picture of the study area using 
Geo-Soft Oasis montaj. manuscript.

\section{A. General Geology of the Study Area}

The study area is dominantly underlain by the Precambrian Basement Complex. However, part of the area is underlain by Cretaceous sediments which unconformably overlie the Basement Complex (Fig 1).

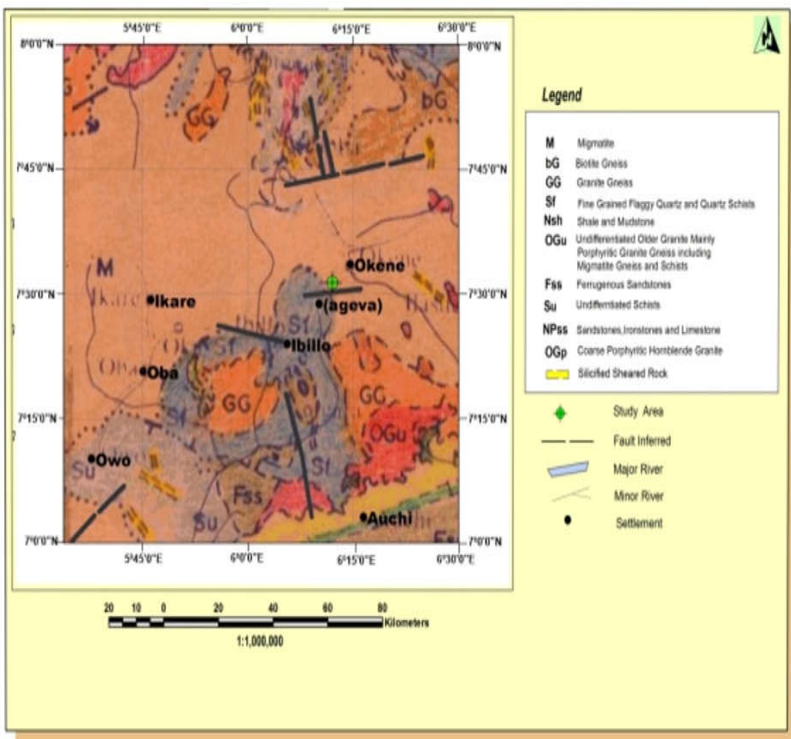

Fig. 1 Geological Map of the Study Area Showing the Location of the Faults [4].

Nigerian basement and ancient hard rocks are made up of crystalline complex rock (gneiss and Migmatite), older metasediment (quartzite, marble calc-silicate and the pan Africa granites/older granites). Migmatite cover about half of the study area outcropping mainly at the northern, eastern and south western parts of the area. The South and the southwestern parts of the area are underlain by undifferentiated older granite, mainly porphyritic granite gneiss, migmatite gneiss and schists with biotite granite, fine grained flaggy quartz and quartz schists. Also present are silicified sheared rocks, shale, mudstones, iron stones, limestones and ferruginous sandstones. The south eastern flank of the area is on the alluvium (youngest and most recent sedimentary rocks) and other sedimentary rocks, which form part of Cretaceous to Recent sediments of Nigeria. The crystalline complex contained economic minerals such as Iron-ore, gem-stones, quartz, feldspar and other associated minerals while the Pan Africa granite/older granite contained cassiterite, tantalite, columbite, gemstones and other associate minerals [5] - [6]. According to [6], the migmatite and gneiss in the Lokoja - Okene area are Eburnean $(+2500 \mathrm{ma})$ and Kibaran (+1000 ma), while the granite, pegmatite and quartz veins are Pan African $(550+100 \mathrm{ma})$ in age. In the discussions of [7] and [8] on the general geology of the Okene area, the dominant lithologic unit in the area is the Migmatite gneiss, overlain by sequence of low-grade metasediments and intruded by granodioritic and granitic rocks. The main rock types identified include granite gneiss, amphibolites, quartzites, schists, granite and pegmatites. Reference [7] discussed the geology of the Itakpe iron-ore deposit, which is localized within the gneiss-migmatite-quartzite unit of the Nigeria basement complex - and identified two types of quartzites in the area: the ferruginous and non-ferruginous. The ferruginous quartzites occur as magnetite-rich and hematite-rich bands and lenses about $10-60 \mathrm{~m}$ wide in alternation with gneisses. The non-ferruginous quartzites are rare on Itakpe, but constitute the bulk of the rock on its southern edge. The three main ore bodies have been delineated which comprises of a group of ferruginous quartzite bands or lenses and all ore bodies crop out at the surface or are capped by thin overburden. The northern ore body occurs at the northern flank of the ridge. It has a strike length of $400 \mathrm{~m}$ and length of $200 \mathrm{~m}$ along dip direction with thicknesses ranging from $30 \mathrm{~m}$ to $60 \mathrm{~m}$. the central ore body extends along strike of $200 \mathrm{~m}$, and it increases in thickness from west to east. Two small ore lenses 35 and $15 \mathrm{~m}$ thick coalesce to form the main ore body which is approximately $40 \mathrm{~m}$ wide. The southern ore body dips steeply to the south and extends along strike for about $500 \mathrm{~m}$ with a thickness of approximately $15 \mathrm{~m}$ and width of about $40 \mathrm{~m}$. The deposit has been folded and faulted and has been affected by regional metamorphism; a general variation in grain size and ore quality from hematite in the west to magnetite in the east is observable, showing an increase in metamorphism eastwards. This accounts for the good quality of the ferruginous quartzite in the eastern part of the ridge.

The Cretaceous sediments within the study area is part of the Middle Niger Basin, which lies within latitude $6^{\circ} 12^{\prime} 00^{\prime \prime} N$ and $7^{\circ} 30^{\prime} 00^{\prime \prime} N$, and longitude $4^{\circ} 12^{\prime} 00^{\prime \prime} E$ and $7^{\circ} 12^{\prime} 00^{\prime \prime} E$. The Middle Niger Basin is a gentle down-warped trough. The buried basement complex probably has a high relief [9] and the sedimentary formations are more than $300 \mathrm{~m}$ thick. The epeirogenesis responsible for the basin genesis seems closely connected with the crustal movements of the Santonian orogeny of South-western Nigeria and nearby Benue Valley. The basin is filled with past-orogenic molasses facies and new thin marine strata, which are unfolded. The original geometry of the basin may have been by Tertiary uplifts which seem to have affected the northern areas more than the southern half. Both the regional dips of the Campanian-Maastrichtian beds and their overall vertical grain size distribution suggest that the original detrital grains were derived from the basement complex of South-western Nigeria. Cases of small-scale faults are locally known [10]. In the work of [10], it was reported that about 7,000 million tons of iron is probably present around Lokoja area alone. A continuous bed of ironstone assaying an average of $50 \%$ iron, $31 \mathrm{ft}$. thick have been proved in the area. It is significant that the overburden in this 
area is relatively low-grade ore, assaying 28.2 to $48.7 \%$ iron. Chemically, the oolitic ironstones of Lokoja area (Agbaja Ironstone Formation) seem to compare favourably with the Minette-type of ores of Europe and North America. They show about 0.8 to $1.3 \%$ phosphorous [9], [11]. Immediately around the belt by Lokoja and in the Okene-Auchi areas are some rich deposits of calcitic marble. Two of the three primary minerals necessary for iron smelting are therefore readily available in and around the Middle Niger Basin. Haematitic ironstones somewhat similar to the Precambrian banded ironstones have also been reported around Okene and Osokso [10]. Mineral deposits can be classified on the basis of the mechanism responsible for concentrating the valuable substance. Examples include: hydrothermal, magmatic, sedimentary, placer and residual mineral deposits. There are two theories on genesis of the deposit. Reference [7] proposed a sedimentary origin in which minerals are concentrated by chemical precipitation from lake or sea water while [12] proposed a magmatic origin in which minerals are concentrated within a body of igneous rock by magmatic processes like crystal settling. Field relationship and drill core observations support the sedimentary origin.

\section{METHODOLOGY}

\section{A. Data Acquisition}

The High Resolution Aeromagnetic (HRAM) data of the study area, sheets 245, 246, 265 and 266, were sourced from the Nigerian Geological Survey Agency (NGSA). The data, covering a degree squared sheet $\left(7^{\circ} 0^{\prime} 00^{\prime \prime}-8^{\circ} 0^{\prime} 00^{\prime \prime} N\right.$ and $5^{\circ} 30^{\prime} 00^{\prime \prime} E-6^{\circ} 30^{\prime} 00^{\prime \prime} E$ ) and in scale of $1: 100000$, were acquired by NGSA at a flight altitude of $80 \mathrm{~m}$, along NE - SW flight lines that were spaced at $500 \mathrm{~m}$. The total magnetic field intensity ranges between 33450 and $32400 n T$. Most of the anomalies trend $\mathrm{E}-\mathrm{W}$, some trend $\mathrm{N}-\mathrm{S}$, and few trend $N W-$ $S E$ and $N E-S W$ at the southern and northern region of the map as shown (Fig. 2). The geologically inferred faults from Fig. 2 are over laid on the aeromagnetic map and labelled (ag) as indicated. A shaded relief image is presented for increased perceptibility of enhancement attributes.

\section{B. Data Processing}

Data processing is the series of steps taken to remove both signal and spurious noise from the data that are not related to the geology of Earth's crust. This process thereby prepares the dataset for the interpretation by reducing the data to only contain signal relevant to the task and these steps include: (i) Regional-residual separation, and (ii) Upward continuation.

\section{i. Regional-residual Correction}

The anomaly field may be closely approximated by leastsquares to eliminate noise. Thus, two equations, one approximating the regional and the other the original function, may be subtracted from one another to obtain an effective bandpass filter [13]. In the least squares method, we are interested in the general tendency of the data, this tendency is used to interpolate between data points, extrapolate beyond the data sequence, infer the presence of trends, or estimate characteristic that may be of interest to the geologists and geophysicist [14]. The least squares criterion regional-residual separation is such that the residual is the square of the deviation of the regional from the observed (measured). The regional uses a polynomial surface to expose the residual features as deviation from the observed field. The separation of a data into two components was done by fitting a trend (plane) surface, which may be defined as a linear function of the geographic coordinates of a set of observations (in this case, total magnetic field data) so constructed that the squared deviations from the trend are minimized.

$Y=b_{0}+b_{1} X_{1}+b_{2} X_{2}$

where the b's are coefficient and the X's are some combination of the geographic coordinates.

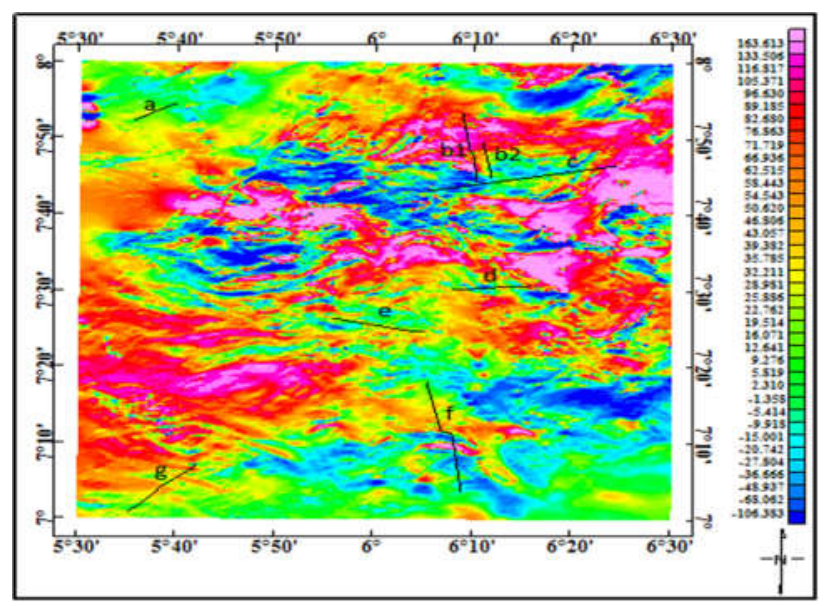

(a)

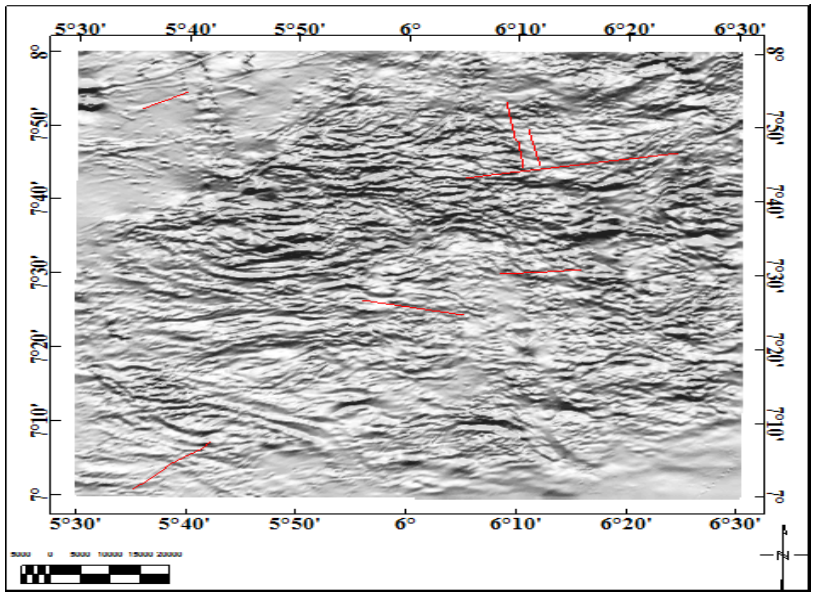

(b)

Fig. 2 (a) Total Magnetic Intensity Map of the Study Area (in +3300 nT), (b) Shaded Relief image of the Total Magnetic Intensity (at elevation $=45^{\circ}$ and illumination declination $=$ $\left.180^{\circ}\right)$ 
Equation (1) thus yield values $(\hat{Y})$ which were the regional components of the observation, which may be regarded as a linear function of some constant value $b_{0}$ related to the mean observations, plus an east-west $\left(b_{1}\right)$ component (in this case, the latitudes) and north-south $\left(b_{2}\right)$ components that is, the longitudes [10].

Hence, we obtain the three normal equations:

$$
\left.\begin{array}{c}
\sum Y=n b_{0}+b_{1} \sum X_{1}+b_{2} \sum X_{2} \\
\sum X_{1} Y=b_{0} \sum X_{1}+b_{1} \sum X_{1}^{2}+b_{2} \sum X_{1} X_{2} \\
\sum X_{2} Y=b_{0} \sum X_{2}+b_{1} \sum X_{1} X_{2}+b_{2} \sum X_{2}^{2}
\end{array}\right\}
$$

In matrix form, the equation becomes:

$$
\left[\begin{array}{ccc}
n & \sum X_{1} & \sum X_{2} \\
\sum X_{1} & \sum X_{1}^{2} & \sum X_{1} X_{2} \\
\sum X_{2} & \sum X_{1} X_{2} & \sum X_{2}^{2}
\end{array}\right] \times\left[\begin{array}{l}
b_{0} \\
b_{1} \\
b_{2}
\end{array}\right]=\left[\begin{array}{c}
\sum Y \\
\sum X_{1} Y \\
\sum X_{2} Y
\end{array}\right]
$$

The least square method was adopted in this work. The solution to (2) for the aeromagnetic survey data was obtained solving the series of simultaneous equation that evolved from the substitution of the sums, sums of powers, and sums of cross-products required in (2). The coefficients $b_{0}, b_{1}$, and $b_{2}$ were found by solving the resulting set of simultaneous normal equations and the coefficients of the plane surface determined are then substituted into (2a) and evaluated to obtain the regional surface $(\hat{Y})$. The differences between the measured or observed field data $(\mathrm{Y})$ and the regional field data $(\hat{Y})$ gives the residual field data. The residual obtained normally consist of positive and negative values. Regionalresidual separation was done with the aid of the Golden Software Surfer version 12.0. The regional field for the aeromagnetic data of interest is presented in Fig. 3(a \& b). It is observed that trend pattern of the regional field is in the $N E-S W$ direction and it decreases southwards. this is in conformity with major tectonic trend in the Nigerian basement complex [6], [14].

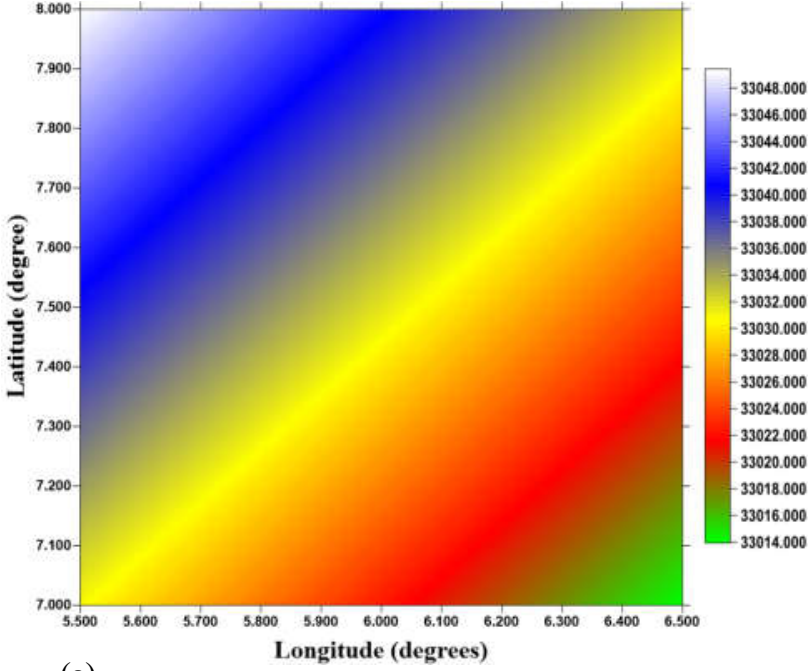

(a)

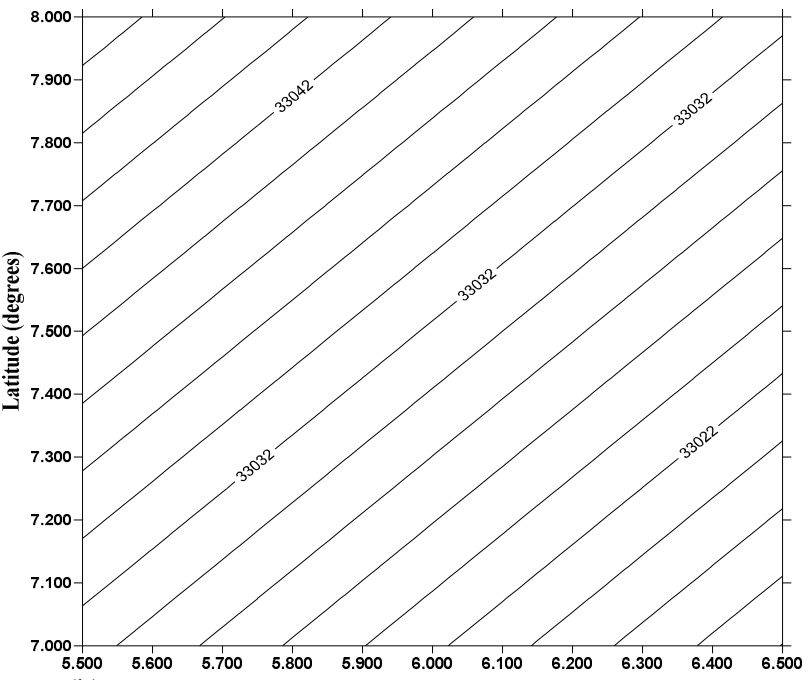

(b)

Longitude (degrees)

Fig. 3 (a) Regional image Map of the Aeromagnetic Data (in $n T$ ) (b) Regional Contour Map of the Aeromagnetic Data.

Contour interval is $50 \mathrm{nT}$.

The residual aeromagnetic data was presented in grid for visualization and further enhancements as shown in Fig. 4a. Shaded relief image of the total magnetic intensity residual map was plotted and examined for its enhancement attributes. The artificial sun elevation (i.e., illumination inclination) was fixed at $45^{\circ}$ above the horizon for all the images while the azimuth (i.e., illumination declination, measured positive clockwise from geographic north), was given a value of $180^{\circ}$. Fig. 4(a \& b) show the results obtained; linear features corresponding to the inferred faults were observed, except for that around Auchi (i.e., fault f). 


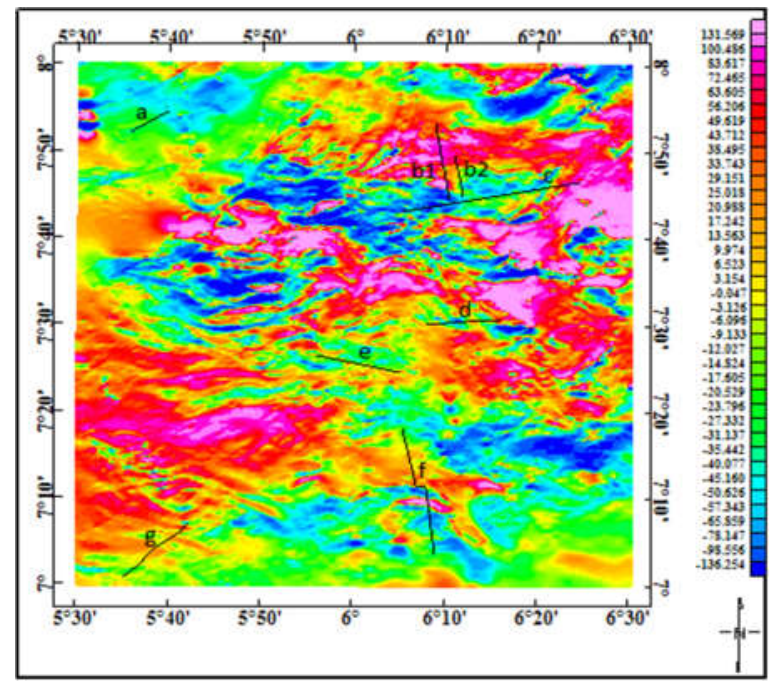

(a)

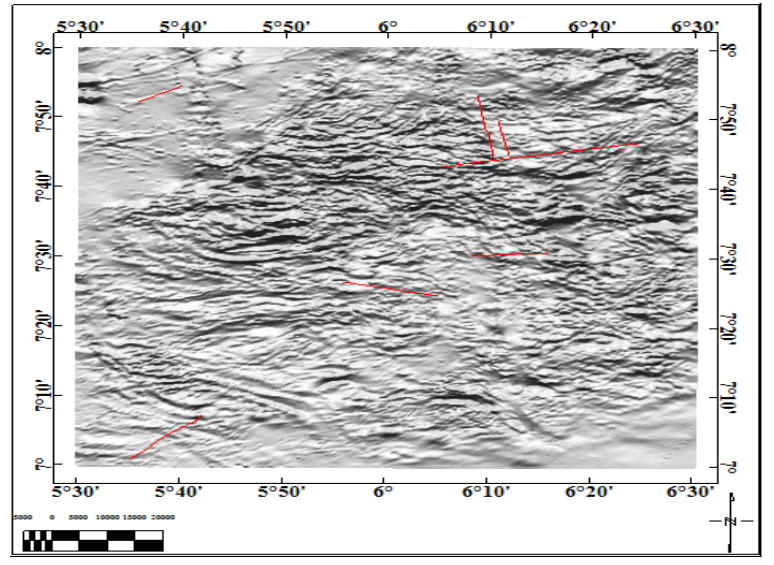

(b)

Fig. 4 (a) Residual image Map of Aeromagnetic Data (in $n T$ )

(b) Shaded Relief image of the Total Magnetic Intensity

Residual (at elevation $=45^{\circ}$, illumination declination $=$ $\left.180^{\circ}\right)$

\section{ii. Upward Continuation}

The reduced aeromagnetic data were upward continued $250 \mathrm{~m}$ as shown in Fig. 5. The data was upward continued to that level for two reasons; (i). The investigated faults have surface expression, hence shallow (ii). Upward continuation at $250 \mathrm{~m}$ reveals a better manifestation of faults within the study area and has also reduced the noise level considerably. The upward continued map illustrates the change in anomaly character with increasing observation to source distance, and also is useful as a low-wave number pass filter. As such, the $250 \mathrm{~m}$ upward continued data provide an excellent integrated view of the study area undistorted by the local, high amplitude, high gradient anomalies of the magnetic sources in the study area. It is apparent that the attenuation of the shallow-source anomalies in the upward continuation process permits a clearer or enhanced view of the deeper anomaly sources.

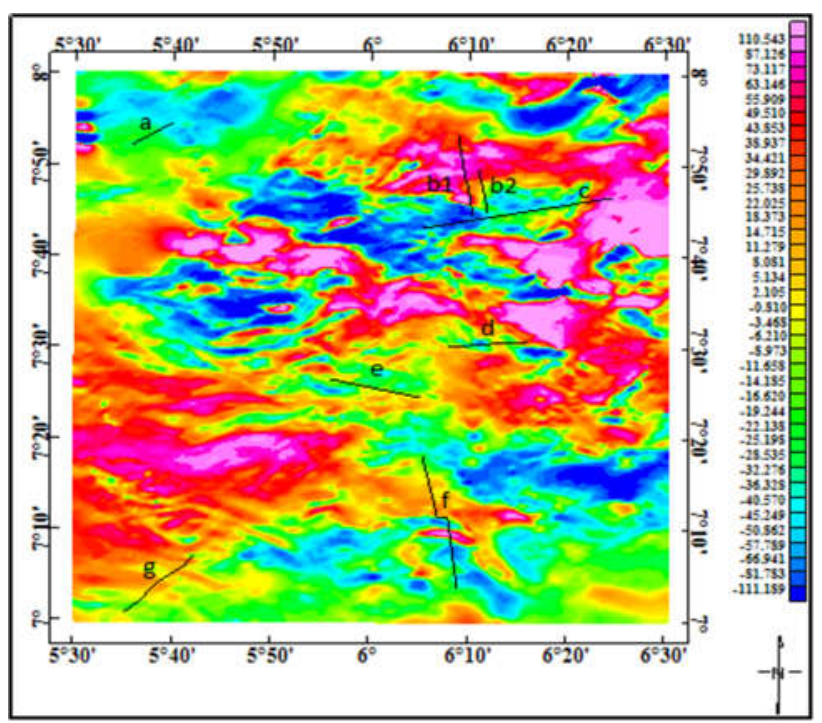

Fig. 5 Upward continued of Aeromagnetic Map to a height of $250 \mathrm{~m}$ (in $n T$ ).

\section{Data Interpretation}

Interpretation techniques employed in this work, includes Second-Vertical derivatives, Analytical signal and Werner deconvolution, involves the inspection of maps of the aeromagnetic data to define boundaries of magnetic units, type of structure existing and its depth.

i. Second Vertical Derivatives

Vertical gradient (Vertical derivative) can be thought of as component of the rate of change of the anomaly values as the potential-field data are upward continued. Nonetheless, vertical-gradient maps help highlight the details, discontinuities and breaks in anomaly texture. Derivatives are intended to outline boundaries.

$$
\Delta T^{\prime \prime}=\frac{\partial^{2}(\Delta T)}{\partial Z^{2}}
$$

$\Delta \mathrm{T}$ and $\mathrm{Z}$ which are the change in magnetic field and vertical displacement respectively, are conventionally used to enhance near-surface effects obscured by the regional trends and also as an aid in the definition of the edges of source bodies. The second vertical derivative has even more resolving power than the first vertical derivative, but its application requires high quality data as its greater enhancement of high frequencies result in greater enhancement of noise. It was shown by [15] that second vertical derivative is zero and rapidly changes sign at a point vertically over the contact. second vertical derivatives delineate the plain-view boundaries of intrabasement anomaly sources and effectively enhances magnetic anomalies [16].

The second vertical derivative of the filtered aeromagnetic data was derived and zero contours of the second vertical 
derivative were distinguished by the red lines (Fig. 6). The zero point of the contour map indicates the spatial locations of the magnetic source edges which in effect outline anomalous areas.

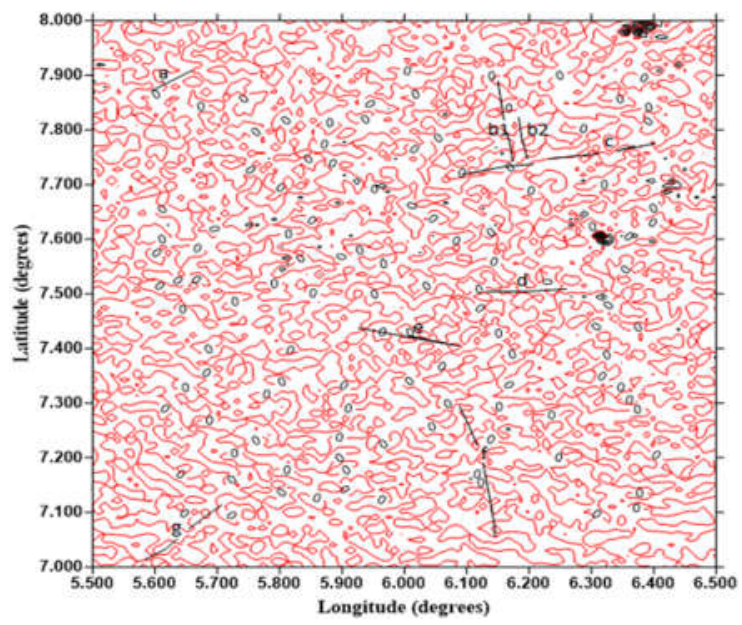

Fig. 6 Second Vertical Derivative Map of the Filtered Aeromagnetic Data

\section{ii. Analytic Signal Technique}

The analytic signal (or total gradient) is the combination of vertical and horizontal gradients. It is based on the calculation of the first derivative of magnetic anomalies to estimate source characteristics. Analytic signal can be used to locate the edges of remanently magnetized bodies, reveal anomalous texture and highlight discontinuities. Analytic signal is a filter applied to magnetic data and is aimed at simplifying the fact that magnetic bodies usually have a positive and negative peak associated with it, which in many cases make it difficult to determine the exact location of the causative body.

Reference [17] introduced the 3-D analytic signal of magnetic data as an extension to the 2-D case and pointed out that the signal exhibits maxima over magnetization contrasts, independent of the ambient magnetic field and source magnetization directions. Reference [18] also suggested a similar view, and claimed that the amplitude of the analytic signal is independent of the inclination of the field in 3-D case. Reference [19] - [22] argued the conclusion that the shape of the analytic signal over 3-D bodies is independent of inclination of magnetization and that the analytic signal response always produces symmetrical anomalies. Reference [23] showed that the shape of the analytic signal of contacts and sheets is independent of the directions of the magnetization and the local geomagnetic field. In addition, [17] showed that this is true for any 2D magnetic anomaly, such is not the case for $3 \mathrm{D}$ anomalies. Nevertheless, the shape of analytic signal is still nearly independent of the directions of magnetization and of the earth's field. Reference [19] calculated the analytic signal of a single magnetic pole anomaly and concluded that; in general, the analytic signal is not symmetric for arbitrary values of inclinations and declination. A circular symmetry is observed for a field inclination of $90^{\circ}$, and at an inclination of $0^{\circ}$; the anomaly is symmetric along the axis of the declination. In general, the anomaly is nearly circular or slightly elongated along the geomagnetic field declination. The Analytic signal of the filtered aeromagnetic data was computed and the map was subsequently (Fig. 7a). The Shaded relief of the Analytic signal map of the filtered aeromagnetic data was also plotted as shown in Fig. $7 \mathrm{~b}$ to clearly show the magnetic behaviour within the study area.

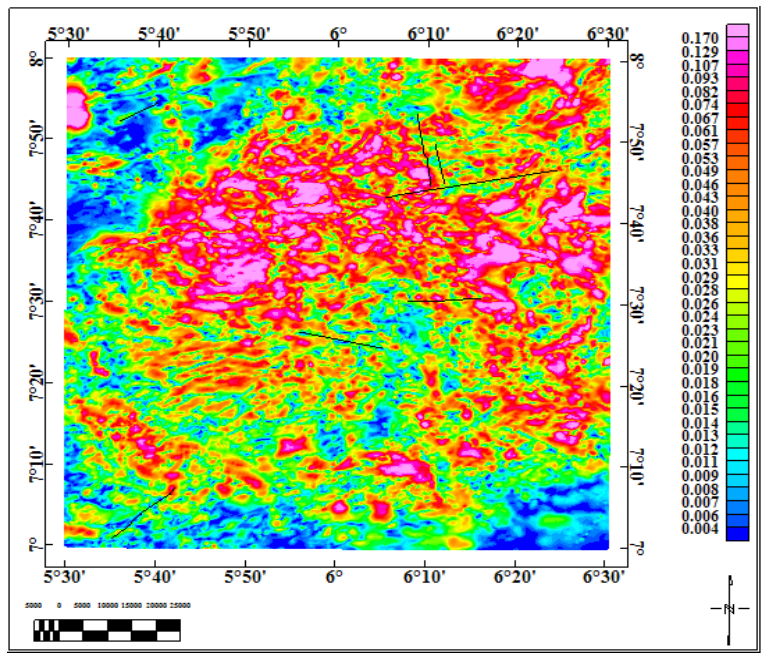

(a)

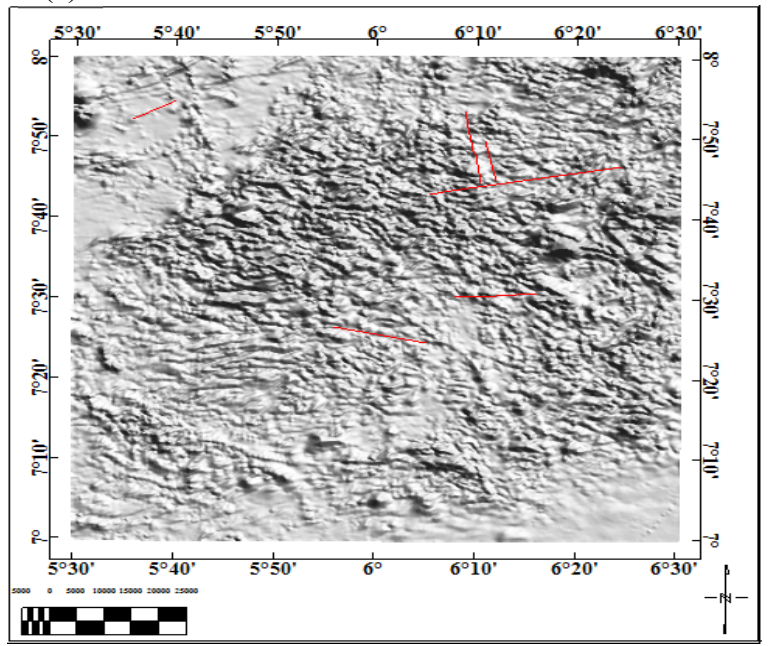

(b)

Fig. 7(a) Analytic Signal Amplitude Map of upward continued Aeromagnetic Data(in $n T / m$ ).(b) Shaded Relief Map of Analytic Signal Data 


\section{iii. Werner Deconvolution}

Reference [24] introduced Werner deconvolution technique, he realized that the greatest need was for a method to separate an anomaly from the interference caused by adjoining anomalies and to consider the entire anomaly in the analysis rather than just a few parameters such as maxima, minima, or inflection points, which can be greatly affected by type of interference. With Werner's method, it is necessary still to assume the type of source configuration, e.g., dykes, and to process the interference correctly. Also, the method assumes initially that the data are perpendicular to geologic strike. The equation of total field for a dyke with infinite strike length and depth extent can be written in the form,

$F(x)=\frac{A\left(x-x_{0}\right)+B z}{\left(x-x_{0}\right)^{2}+z^{2}}$

Where $x$ represents distance along a profile and $\mathrm{F}$ is the total magnetic field intensity at $x$. The A and B are functions of the field strength, susceptibility, and the geometry involved (dip, strike, magnetic inclination, declination, etc.); $x_{0}$ is the horizontal distance along traverse to the point immediately above the top of the dyke; and $\mathrm{z}$ is the depth to the top of the dyke. There are four unknown quantities: $A, B, x_{0}, z$.

Werner points out that in the simple case where observations are made in a level plane over level bounded bodies whose length and depth are infinite and whose strike is perpendicular to the direction of the profile, the equation for a dyke can be cast into the following interpretation equation:

$a_{o}+a_{1} x+b_{0} F+b_{1} x F=x^{2} F$

In this equation, $x$ and $F$ are the same as in (5). It follows that

$$
\left.\begin{array}{c}
a_{0}=-A x_{0}+B z \\
a_{1}=A \\
b_{0}=-x_{0}^{2}-z^{2} \\
b_{1}=2 x_{0}
\end{array}\right\}
$$

Conversely, the depth and horizontal position of the top of the dyke are functions of the parameters of the interpretation in (6):

$$
\mathrm{z}= \pm \sqrt{-4 b_{0}-b_{1}^{2}} \text { and } x_{0}=\frac{1}{2} b_{1}
$$

Since there are four unknowns, simultaneous solution of the interpretation in (5) at four $x$ values and their corresponding $\mathrm{F}$ values will yield solutions for $a_{0}, a_{1}, b_{0}$, and $b_{1}$ from (6) and for $x_{0}$ and $z$ from (7), In the simple case, the geometric solution is complete and the depth to the top of the dyke (thin sheet) has been determined.

If we now admit the possibility of interference and assume that the interference can be represented by a polynomial of some degree, we can add the interference polynomial to (4).
$F(x)=\frac{A\left(x-x_{0}\right)+B z}{\left(x-x_{0}\right)^{2}+z^{2}}+C_{0}+C_{1} x+\cdots+C_{n} x^{n}$

Where $\mathrm{n}$ is the order of the interference polynomial and the C's are the coefficients. We now have a total of $(n+5)$ unknowns and therefore $(n+5)$ points are required to solve for the unknowns. In practice, a first or second order polynomial is generally sufficient, so that 6 or 7 points are required for solution. Werner also presents a simple method of solving the simultaneous equations which amounts to multiplying the data points by a set of linear operators, thus greatly reducing the labour involved. Although this represents the first attempt to deal automatically with interference, with Werner's method it is necessary still to assume the type of source configuration e.g., dykes, and to process the interference correctly. Also, the method assumes initially that the data are perpendicular to geologic strike [25]. We also applied Werner deconvolution [24] to the aeromagnetic data. This technique is very useful and simple for preliminary interpretation of potential field data for isolated bodies. It assumes that the source is a vertical thin dyke sheet-like body but it is feasible to model thick bodies as well; by assuming that the body consists of several thin dykes. The usefulness of the method is enhanced by the fact that the horizontal gradient of the total field caused by edge of a thick body is equivalent to the total field from a thin dyke. This technique is much appreciable because it does not require any initial model for the interpretation [26]. The Werner deconvolution applied directly on the magnetic profile at equal linear intervals [25] to estimate four parameters of 2D bodies, similar to dykes and contacts such as faults and fractures: horizontal location, depth, dip, and magnetic susceptibility. The sensitivity of the operator, as earlier stated, for the detection of an anomalous geologic source will be strongly related to the horizontal distance subtended by the array: the broader a given anomaly, the larger must be the dimension of the array required to recognize it. For this reason, the computation sequence described above is repeated a number of times, with the operator length (distance between points in the array) increased each time.

The concept, however, seems fundamentally sound [27] - [28], using model data, has shown that the accuracy of the depth determinations is approximately $10 \%$. Eleven profiles were extracted from upward continued map, perpendicular to the direction of the geologically identified faults within the study area, as shown in Fig. 8 and were subsequently subjected to Werner deconvolution. 


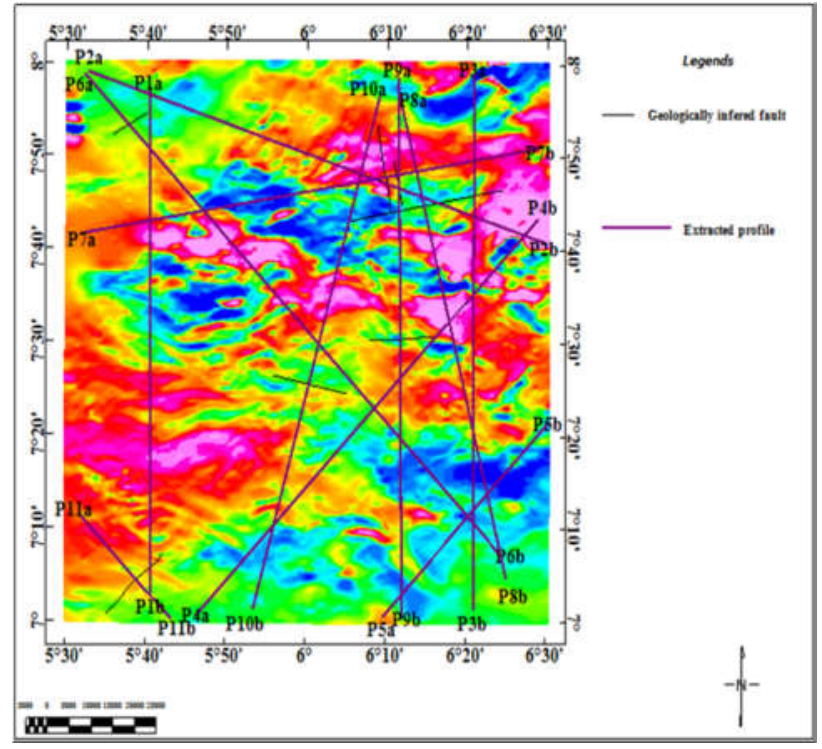

Fig. 8 A layout of the profiles on the Upward continued aeromagnetic data.

The Werner deconvolution of the eleven profiles from the filtered aeromagnetic data which solves for contact and dyke were computed using OASIS MONTAJ ${ }^{\mathrm{TM}}$ (Fig. 9 (a - k)). The Werner solutions of the profiles were subsequently posted on Upward continued map (Fig. 10) to trace their intersections with the identified faults within the study area.

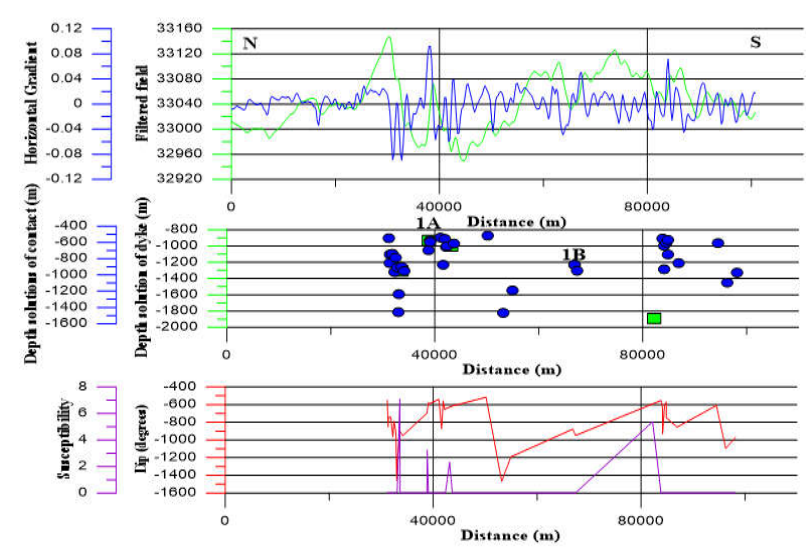

Fig. 9(a) Werner Solution of Profile One
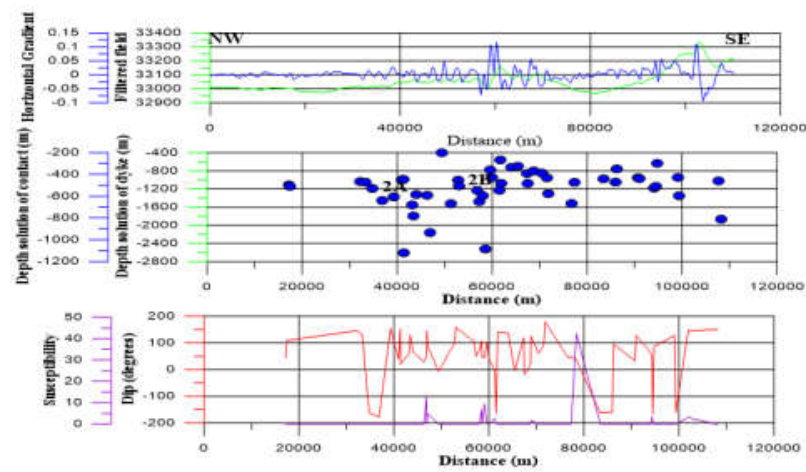

Fig. 9 (b) Werner Solution of Profile Two

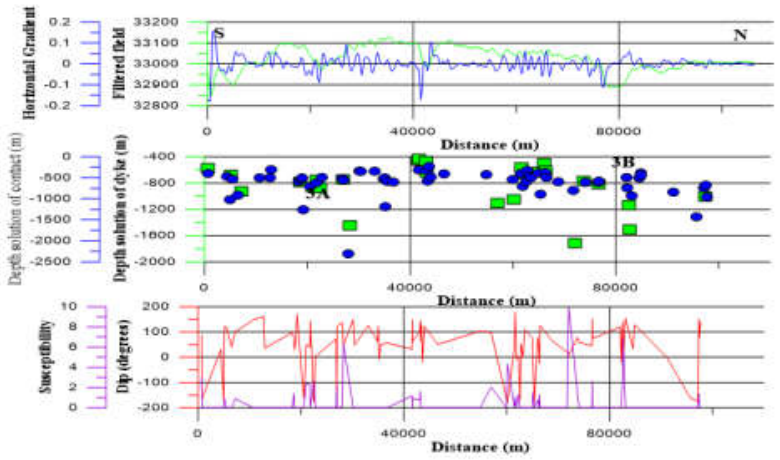

Fig. 9 (c) Werner Solution of Profile Three

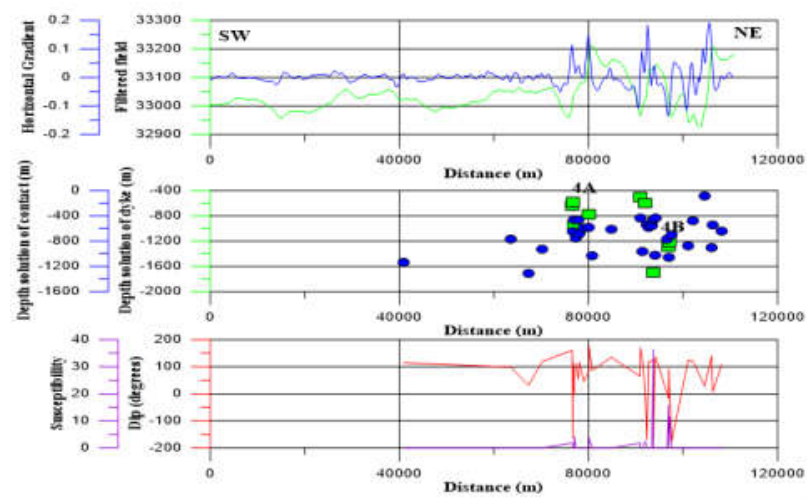

Fig. 9 (d) Werner Solution of Profile Four 


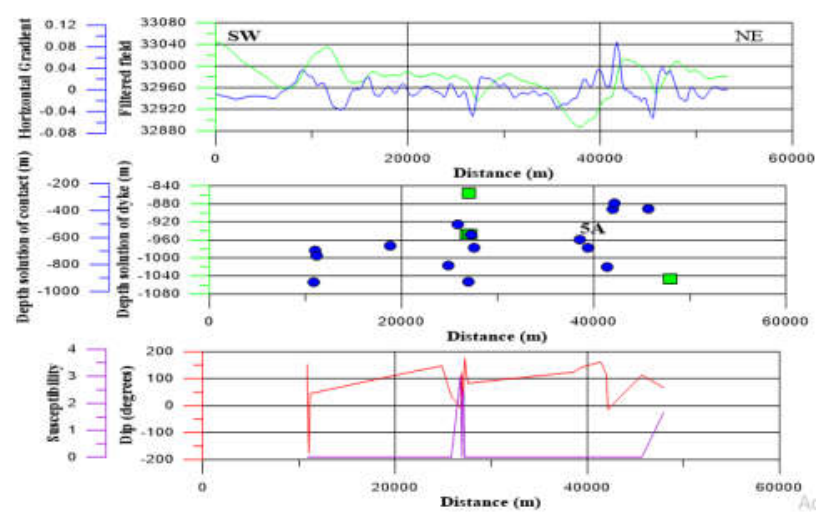

Fig. 9 (e) Werner Solution of Profile Five

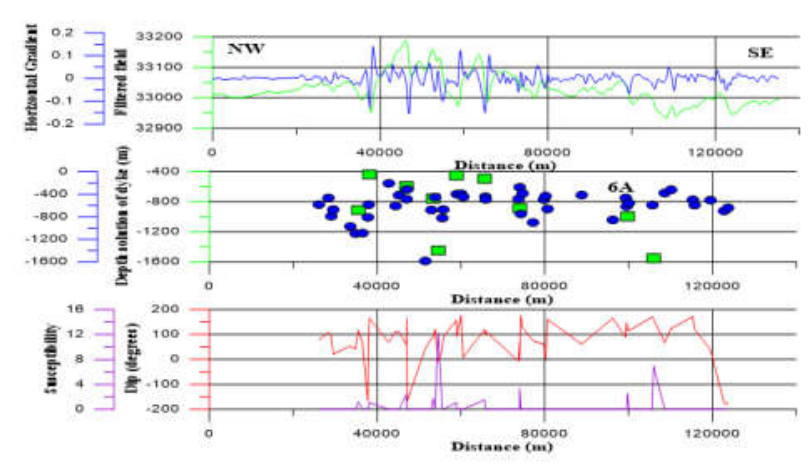

Fig. 9 (f) Werner Solution of Profile Six

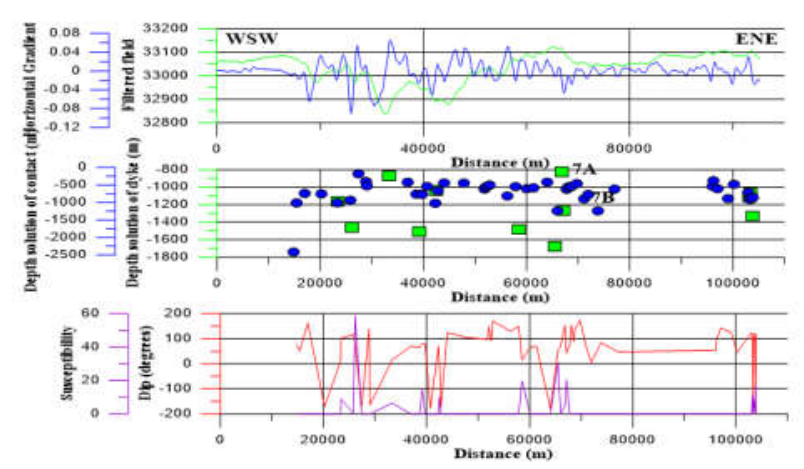

Fig. 9 (g) Werner Solution of Profile Seven

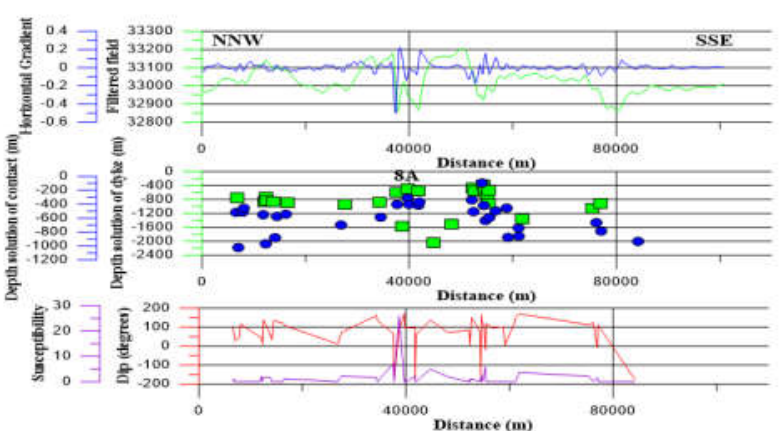

Fig. 9 (h) Werner Solution of Profile Eight
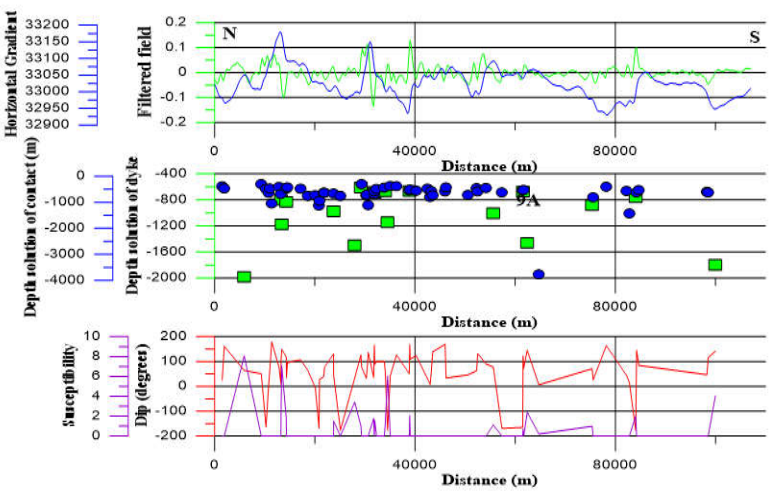

Fig. 9 (i) Werner Solution of Profile Nine
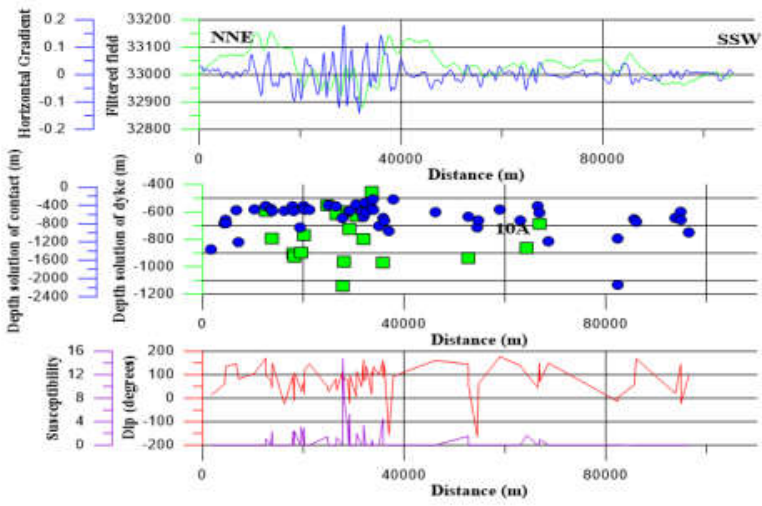

Fig. 9 (j) Werner Solution of Profile Ten 


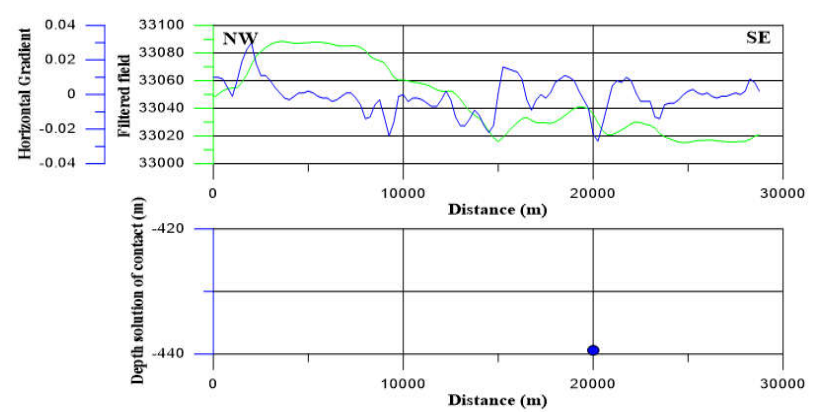

Fig. 9 (k) Werner Solution of Profile Eleven

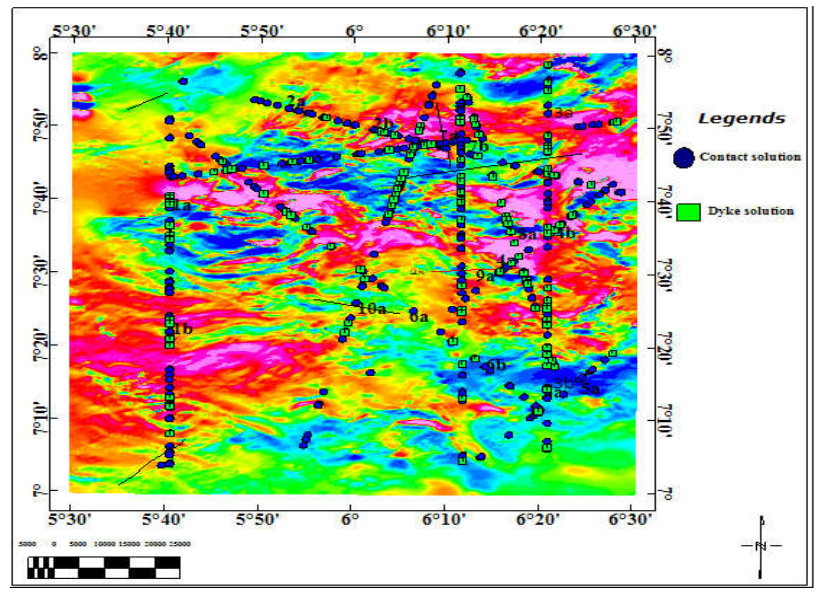

Fig. 10 A post of Werner Solutions on the Upward Continued Map of Study Area

The characteristics of the Werner solutions at the points where the selected profiles intersect the inferred faults are presented in Table I below.

TABLE I CHARACTERISTICS OF THE WERNER SOLUTIONS AT THE POINTS OF INTERSECTION

\begin{tabular}{cccccc}
\hline S/N & $\begin{array}{c}\text { Intersection } \\
\text { Point }\end{array}$ & Werner Type & Depth (m) & Dip ( ${ }^{\circ}$ ) & $\begin{array}{c}\text { Susceptibility } \\
\text { (SI) Units }\end{array}$ \\
\hline 1 & $1 \mathrm{~A}$ & Dyke & 826 & 40.2 & 1.9237597 \\
2 & $1 \mathrm{~B}$ & Dyke & 982.5 & 32.2 & 1.9532233 \\
3 & $2 \mathrm{~A}$ & Contact & 607.4 & 154.9 & 0.0010823 \\
4 & 2B & Contact & 649.8 & 49.7 & 0.0132357 \\
5 & 3A & Contact & 539.0 & 28.4 & 0.0020078 \\
6 & 3B & Contact & 742.5 & -21.6 & 0.0030063 \\
7 & 4A & Contact & 593.2 & 45.4 & 0.0030234 \\
8 & 4B & Contact & 435.7 & 136.6 & 0.0015891 \\
9 & 5A & Contact & 675.6 & 142.2 & 0.0024060 \\
10 & 6A & Contact & 414.0 & 60.6 & 0.0010072 \\
11 & $7 \mathrm{~A}$ & Contact & 539.5 & 88.7 & 0.0039155 \\
12 & $7 \mathrm{~B}$ & Contact & 775.0 & 6.2 & 0.0035164 \\
13 & $8 \mathrm{~A}$ & Contact & 401.5 & 97.7 & 0.0016350 \\
14 & $9 \mathrm{~A}$ & Contact & 718.2 & 46.3 & 0.0017500 \\
15 & $10 \mathrm{~A}$ & Contact & 491.4 & 176.7 & 0.0014566 \\
\hline \hline
\end{tabular}

A. A Second vertical derivative calculations were performed on the aeromagnetic data as shown in Fig. 6. The second vertical derivative analysis provides a means of discriminating local features while suppressing broad and regional structures. Discontinuities were observed around the geologically inferred faults.

B. The analytic signal amplitude has been reported to be useful for outlining the gross shape of some features [29] [30]. Lineaments trending along some inferred faults (a, c, d, e and g) were observed as shown in Fig. 7(a \& b). Marginal lineaments were observed within the inferred faults within Ageva (fault d) and Owo (fault g) which implies that the faults may be mineralized.

Fig. $7 \mathrm{~b}$ also suggest probable extension of the inferred faults at Ibilo (fault e) and Ageva (fault d) by a quarter of their exposed lateral extent. Werner deconvolution method was applied along profiles $(1-11)$ of the filtered aeromagnetic data. The same parameters were applied to all profiles. A high residual cut-off was applied which is a variable required to generate fewer solutions of Werner deconvolution. The following could be inferred from the result shown in Fig. 9 (a - k). Werner solutions were produced at the point of intersection with all target linear trends except fault ' $a$ '. The Werner solutions at the intersection point 7A, 7B \& 2B with the faults above Okene (faults b1, b2 \& c) are in form of Contact, with depth extent of $539.5 \mathrm{~m}$ to $775 \mathrm{~m}$ and relatively show high susceptibilities. The solutions at the intersection points 9A and 4A; inferred fault within Ageva fault ' $d$ ' suggests a Contact with low susceptibility at depth of about $718.2 \mathrm{~m}$ and probably a vertical Dyke (high dip) with very high susceptibility at depth of about $900 \mathrm{~m}$. The solutions at the intersection point $10 \mathrm{~A}$ and $6 \mathrm{~A}$ with the inferred fault within Ibilo fault 'e' suggest a probable vertical Dykes with low susceptibilities while the Werner solution that intersect fault within Owo fault ' $\mathrm{g}$ ' indicates Contact with very low susceptibility. The linear features at western edge are characterized by dykes of high susceptibility values (points $1 \mathrm{~A}$ and $1 \mathrm{~B})$. The linear features at the northeastern edge (3A) are characterized by low dip (non-vertical contact). The range of the depth extent of linear features is $401.5-982.5 \mathrm{~m}$.

\section{ACKNOWLEDGMENT}

The This work could not have been completed without the assistance of Mr. Ebuka of the Nigeria geological survey agency (NGSA) Abuja and Mr. Abdul of the cartography department of NGSA Kaduna. The authors are very thankful.

\section{References}

[1] A. Reeves, "Olympic Dam Copper-Uranium GoldSilver Deposit. In: Hughes, F. E., Ed., Geology of the Mineral Deposits of Australia and Papua New Guinea". The Australasian Institute of Mining and Metallurgy, pp. 1009 - 1035, 1990. 
[2] M. M. El-awady, H. El-etr, and A. Bakrah, "Aeromagnetic geophysical investigation in ElFaiyum district, western desert, Egypt". Qatar University Science Bulletin, vol. 5, pp. 335 - 356, 1984.

[3] R. M. Peterson, "New Methods for Interpretation of geologic structures from Landsat imagery". Geophysics, vol. 41, pp. 369 - 370, 1976.

[4] Nigeria Geological Survey Agency (NGSA). Geological map Records by Nigeria Geological Survey Agency, Kaduna State, Nigeria, 2005.

[5] Kogi State Ministry of Solid Minerals Development (KSMSMD. Now Ministry of Special Duties), Kogi State minerals investment prospects, vol. 49, 2005.

[6] M. Caen-Vachette, and B. N Ekwueme, "Pathogenesis of Schists in south east Lokoja, Central Nigeria". Global Journal of Geological Sciences, vol. 1, no. 1, pp. 29-42, 1998.

[7] M. A. Olade, "General features of Precambrian iron ore deposits of Itakpe ridge, Okene, Nigeria". Transnational Institution of Mineral and Metallurgical Section Bulletin, vol. 87, no. B1 - B9, 1978.

[8] A. E. Annor, and S. J. Freeth, "Thermotectonic evolution of the Basement Complex around Okene Nigeria with special reference to deformation mechanism". Precambrian Research, vol. 28, pp. $269-281,1985$.

[9] H. A. Jones, "The occurrence of Oolitic Ironstones in Nigeria: Their Origin, Geological History and Petrology". Ph.D. dissertation. Oxford Univ., UK, 1955.

[10]D. R. Adeleye, "The Geology of the Middle Niger Basin". In: Kogbe, C.A., Ed., Geology of Nigeria (second revised edition), Rock View International, France, pp. $335-339,1975$.

[11]H. A. Jones, "The Oolitic Ironstones of Agbaja Plateau, Kabba Province". Geological Survey of Nigeria, pp. $20-43,1958$.

[12] A. Mucke, and U. Newmann, "The genesis of the banded iron ore deposits of Itakpe area, Kwara State, Nigeria". Forthschite der Mineralgie, vol. 64, pp. $187-204,1986$.

[13] W. J. Hinze, "The Role of Gravity and Magnetic Methods in Engineering and Environmental Studies". In; Ward, S. H., Ed., Geotechnical and Environmental Geophysics, 1, Society of Exploration Geophysicists, pp. $75-126,1990$.

[14]J. C. Davis, "Statistics and Data Analysis in Geology". John Wiley and Sons Incorporation, New York, pp. $44-120,1973$.

[15]P. Hood, and D. J. McClure, "Gradient Measurements in Ground Magnetic Prospecting. Geophysics, vol. 30, no. 3, pp. $403-410,1965$.

[16]R. A. Sharma, A Comprehensive System of Automatic Computation in Magnetic and Gravity Interpretation: Geophysics, vol. 25 no. 3, pp. $569-$ $585,2002$.
[17] W. R. Roest, J. Verhoef and M. Pikington, "Magnetic interpretation using the 3-D analytic signal". Geophysics, vol. 57, pp. 116 - 125, 1992.

[18] S. Qin, "An analytic signal Approach to the Interpretation of Total Field Magnetic Anomalies". Geophysics Prospecting, vol. 42, pp. 665 - 675, 1994.

[19] B. N. P. Agarwal and R. K. Shaw, "Comment on: An analytic signal approach to the interpretation of total magnetic anomalies" by Shuang Qin: Geophysical Prospecting, vol. 44, pp. 911 - 914, 1996.

[20]Z. N. Guan and C. L. Yao, "Inversion of the total gradient modulus of magnetic anomaly due to dipping dike. Earth Science Journal of China University of Geoscience, vol. 22, no. 1, pp. 81 - 85, 1997.

[21] L. P. Huang, Z. N. Guan, and C. L. Yao, "Comment on: An analytic signal approach to the interpretation of total field magnetic anomalies' by Shuang Qin. Geophysical Prospecting, vol. 45, no. 5, pp. 879 881, 1997.

[22] L. P. Huang and Z. N. Guan Discussion on: "Magnetic interpretation using the 3-D analytic signal". Geophysics, vol. 63, no. 2, pp. $667-667$, 1998.

[23] M. N. Nabighian, "The Analytic signal of TwoDimensional Magnetic bodies with Polygonal crosssection: Its Properties and Use for Automated Anomaly Interpretation". Geophysics, vol. 37, pp. $507-517,1972$.

[24] S. Werner, "Interpretation of magnetic anomalies of sheet like bodies". Sverige Geologiska Undersökning Serie C, Arsbok, vol. 43, no. 6, pp. 66 $-97,1953$.

[25] R. R. Hartman, D. J. Teskey, and J. Friedberg, "A system for rapid digital aeromagnetic interpretation". Geophysics, vol. 36, pp. $891-918$.

[26] C. Ku, and J. A. Sharp, "Werner deconvolution for automated magnetic interpretation and its refinement using Marquardt's inverse modelling". Geophysics, vol. 48, pp. $754-774,1983$.

[27] P. J. Gunn, Application of aeromagnetic surveys to sedimentary basin studies. Journal Australian Geology and Geophysics, vol. 17, pp. 133 - 144, 1997.

[28] S. Jain, An automated method of direct interpretation of magnetic profiles. Geophysics, vol. 41, pp. 531 $541,1974$.

[29] S. C. Wijn, C. Perez and P. Kowalczyk, Theta map: Edge detection in magnetic data. Geophysics, vol. 70, no. 4, pp $39-43,2005$.

[30] P. Keating, and P. Sailhac, "Use of the analytic signal to identify magnetic anomalies due to kimberlite pipes". Geophysics, vol. 69, no. 1, pp. $180-190$, 2004. 